\title{
Pictograms for Safer Medication Management by Health Care Workers
}

\author{
Régis Vaillancourt, Annie Pouliot, Kim Streitenberger, Sylvia Hyland, and Pierre Thabet
}

\begin{abstract}
Background: Inherent risks are associated with the preparation and administration of medications. As such, a key aspect of medication safety is to ensure safe medication management practices.

Objective: To identify key medication safety issues and high-alert drug classes that might benefit from implementation of pictograms, for use by health care providers, to enhance medication administration safety. This study was the first step in the development of such pictograms.

Methods: Self-identified medication management experts participated in a modified Delphi process to achieve consensus on situations where safety pictograms are required for labelling to optimize safe medication management. The study was divided into 3 phases: issue generation, issue reduction, and issue selection. Issues achieving at least $80 \%$ consensus and deemed most essential were selected for future studies. Retained issues were subjected to semiotic analysis, and preliminary pictograms were developed.
\end{abstract}

Results: Of the 87 health care professionals (pharmacists, pharmacy technicians, nurses, and physicians) invited to participate in the Delphi process, 30 participated in all 3 phases. A total of 55 situations that could potentially benefit from safety pictograms were generated initially. Through the Delphi process, these were narrowed down to 10 situations where medication safety might be increased with the use of safety pictograms. For most of the retained issues, between 3 and 6 pictograms were designed, based on the results of the semiotic analysis.

Conclusions: The pharmacists, pharmacy technicians, nurses, and physicians participating in this study reached consensus and identified 10 medication administration safety issues that might benefit from the development and implementation of safety pictograms. Pictograms were developed for a total of 9 issues. In follow-up studies, these pictograms will be validated for comprehension and evaluated for effectiveness.

Keywords: pictogram, Delphi process, medication safety, medication error, health care worker

\section{RÉSUMÉ}

Contexte : Il y a des risques inhérents associés à la préparation et à l'administration de médicaments. Pour cette raison, l'un des principaux aspects de la sécurité des médicaments est d'assurer des pratiques de gestion des médicaments sécuritaires.

Objectif: Déterminer les principales questions de sécurité des médicaments et les classes de médicaments de niveau d'alerte élevé pour lesquelles l'ajout de pictogrammes, destinés aux fournisseurs de soins de santé, permettrait de rendre l'administration de médicaments plus sécuritaire. La présente étude représentait la première étape dans l'élaboration de ces pictogrammes.

Méthodes : Des professionnels qui se définissaient comme experts en gestion de médicaments ont participé à un processus Delphi modifié dans le but d'arriver à un consensus à propos des situations où des pictogrammes de sécurité doivent être ajoutés à l'étiquette afin d'optimiser la gestion sécuritaire des médicaments. L'étude a été divisée en trois phases : génération de questions de sécurité, élimination de questions de sécurité et sélection de questions de sécurité. Les questions qui atteignaient un consensus d'au moins $80 \%$ et qui étaient considérées comme les plus essentielles ont été retenues pour des études ultérieures. Les questions de sécurité retenues ont été soumises à une analyse sémiotique, puis des ébauches de pictogrammes ont été créées.

Résultats : Parmi les 87 professionnels de la santé (notamment des pharmaciens, des techniciens en pharmacie, du personnel infirmier et des médecins) invités à participer au processus Delphi, 30 ont pris part aux trois étapes. Au total, 55 situations pour lesquelles il pourrait être avantageux d'utiliser des pictogrammes de sécurité ont été générées au départ. Grâce au processus Delphi, ce nombre a été réduit à 10 situations pour lesquelles la sécurité des médicaments pourrait être accrue à l'aide de pictogrammes de sécurité. Pour la plupart des questions retenues, entre trois et six pictogrammes ont été conçus à l'aide des résultats de l'analyse sémiotique.

Conclusion : Les pharmaciens, les techniciens en pharmacie, le personnel infirmier et les médecins qui ont participé à l'étude ont atteint un consensus sur dix questions au sujet de l'administration sécuritaire des médicaments pour lesquelles l'élaboration et la mise en place de pictogrammes de sécurité pourraient être avantageuses. Ensuite, des pictogrammes ont été conçus pour neuf questions au total. Dans les études ultérieures, il faudra évaluer l'efficacité des pictogrammes et s'assurer qu'ils sont interprétés correctement.

Mots clés : pictogramme, processus Delphi, sécurité des médicaments, erreur de médicament, travailleur de la santé 


\section{INTRODUCTION}

$\mathrm{T}$ o achieve optimal pharmaceutical treatment, a patient must receive the correct drug, in the correct strength, at the correct time. ${ }^{1}$ Often, however, one or more of these conditions are not met, and medication administration is associated with a high number of medication errors. ${ }^{2-4}$ During hospital stays, about $5 \%$ of patients experience medication errors, which occur during prescribing, transcribing, dispensing, or administration; together, these medication errors represent a strong risk factor for adverse drug events. ${ }^{1,5}$

In recent years, the analysis of medication incidents has shifted to a systems-based approach, which focuses on the underlying causes of medication errors rather than identifying the individuals who have made the errors. ${ }^{6}$ Tools and resources must be made available to reduce the potential for medication errors, such as those encountered by health care professionals during medication management. Cautionary pictograms from the Globally Harmonized System of Classification and Labelling of Chemicals ${ }^{7}$ are already in use by the Workplace Hazardous Materials Information System to increase workplace safety during handling of chemicals. ${ }^{8}$ A similar suite of pictograms to alert health care professionals during medication management may optimize medication safety, especially during medication administration. Studies have shown that pictograms, when combined with training, increase memory recall of medical instructions; this property makes safety pictograms ideal tools for the improvement of medication management by health care providers. ${ }^{9}$

Through consultation with a panel of medication management experts, we aimed to establish a universally accepted set of safety pictograms. The objective of the current study was to identify key medication safety issues and high-alert drug classes that might benefit from cautionary identifiers, as recognized by a national panel of experts. ${ }^{10}$

\section{METHODS}

The Delphi technique was used to achieve consensus about which medication safety issues and high-risk drug categories would require pictograms. The Delphi process used in this study was divided into 3 distinct phases: issue generation (phase 1), issue reduction (phase 2), and issue selection (phase 3). The Delphi process was followed by a fourth phase, semiotic analysis and pictogram development.

Health care professionals involved in medication management were targeted for this study, and pharmacists, pharmacy technicians, nurses, and physician anesthesiologists were the principal participants. A broad invitation was sent to target participants via the Institute for Safe Medication Practices Canada (ISMP Canada) Safety Bulletin. Pharmacy directors of hospitals in the Medbuy group (www.medbuy.ca/) received an e-mail invitation to participate in the study and were also asked to distribute the invitation within their respective departments. All interested participants were required to reply as a demonstration of interest and to self-identify as a medication management expert. Health care professionals from across Canada were included in the panel of experts to help achieve a national consensus on medication safety pictograms.

\section{Data Collection}

Data collection took place in Ottawa, Ontario, over the 6-month period from January to June 2015. Ethics approval for the project was obtained from the Children's Hospital of Eastern Ontario Research Ethics Board. Surveys for all 3 phases were sent to participants using REDCap, a secure web-based application designed to build and manage surveys and databases. ${ }^{11}$ Data were collected with REDCap version 6.4.6 and were then exported to Microsoft Excel 2010 (Microsoft, Redmond, Washington) for analysis.

\section{Phase 1: Issue Generation}

A preliminary list of 14 issues (Table 1), previously identified by ISMP Canada (K.S., S.H.), was proposed to participants during the first phase of the Delphi process. Participants were asked to select issues that they agreed would benefit from a pictogram and to specify other medication management issues or high-alert drug classes that might benefit from medication administration safety pictograms.

\section{Table 1. Medication Safety Issues and High-Alert Drug Classes Identified by the Institute for Safe Medication Practices Canada as Requiring Additional Warning}

Issues Requiring Additional Warning

- Drug that must always be diluted before administration

- Drug that can be administered by only one route

- Multi-part drug (e.g., vaccine and diluent)

- Drug that requires airway management before administration

- Drug names that look alike

- Drug names that sound alike

- Drugs that look alike
High-Alert Drug Classes

- Neuromuscular blocking agent

- Antithrombotic agent

- Antineoplastic agent

- Anesthetic agent

- Insulin

- Opioid

- Concentrated electrolyte formulation 


\section{Phase 2: Issue Reduction}

Phase 2 of the survey was sent to all those who responded during phase 1 . This phase of the survey was populated with the medication safety issues and high-alert drug classes obtained from ISMP Canada along with any issues that were suggested more than once by participants during phase 1 .

In the phase 2 survey, participants were asked to rate each issue on a 5-point Likert scale with regard to the need for a safety pictogram, where $1=$ strongly disagree that a pictogram is needed, 2 = disagree, $3=$ neither agree nor disagree, $4=$ agree, and $5=$ strongly agree. To allow the data to better represent each profession, the data were analyzed by groups of health care professionals (i.e., pharmacists, pharmacy technicians, nurses, physicians), and issues that attained at least $80 \%$ agreement within at least one health care profession were retained for phase 3. Agreement was defined as at least $80 \%$ of participants agreeing (score of 4) or strongly agreeing (score of 5) that a safety pictogram would be beneficial for a given topic.

\section{Phase 3: Issue Selection}

Phase 3 of the survey was populated with issues retained from phase 2 and was then sent to all participants who responded during phase 2. Participants were asked to rate each issue in terms of its "pictogram essentialness" on a 100-point visual analogue scale, where $0=$ non-essential, $50=$ indifferent, and $100=$ essential. Mean essentialness scores, which measured the perceived need for a pictogram, were used to determine the top 10 medication safety issues. These 10 most essential issues were retained at the end of phase 3 for semiotic analysis and pictogram development, as it was thought that these would yield the most benefit.

\section{Phase 4: Semiotic Analysis and Pictogram Development}

Issues retained from phase 3 were subjected to semiotic analysis, whereby the Google and Yahoo search engines were used to identify images and then analyze graphic elements used in the visual depiction of the retained issues. The top 20 images from these searches most relevant to the retained issues were analyzed for common themes. ${ }^{12}$ Thematic elements present in more than $50 \%$ of the images were shared with a graphic designer to guide pictogram development. Preliminary pictograms were sent to all of the health care professionals who had participated in at least one phase of the Delphi process. These experts were asked to select their preferred pictographic representation of each medication administration safety issue and to comment on how to improve each pictogram.

\section{RESULTS}

The survey was initially sent to 87 health care professionals. Participants who responded to the phase 1 survey were invited to participate in the subsequent phases (Table 2).

\section{Phase 1: Issue Generation}

Fifty-four medication management experts completed the phase 1 survey, suggesting a total of 30 medication safety issues and 11 high-alert drug classes that required pictograms, for a total of 41 issues. With the addition of the 14 issues suggested by ISMP Canada, a total of 55 issues were generated for phase 2.

\section{Phase 2: Issue Reduction}

Thirty-five of the participants completed the phase 2 survey. Of the 55 issues presented, 7 issues attained at least $80 \%$ agreement within all 3 health care professions, 6 attained at least $80 \%$ agreement in 2 health care professions (nursing and pharmacy), and 7 issues attained at least $80 \%$ in one health care profession (pharmacy or nursing) (Table 3). These 20 issues were retained for the phase 3 survey.

\section{Phase 3: Issue Selection}

Thirty of the participants completed the phase 3 survey, and the top 10 issues deemed the most essential were retained (Table 4). As such, the group of experts reduced the number of issues for pictogram development by half and selected the issues with the greatest need for and the greatest potential benefit from pictogram development. All 10 of the issues retained had an essentialness score greater than 70 .

Table 2. Distribution of Medication Management Experts Who Participated in All 3 Phases of the Delphi Process

\begin{tabular}{lrrrr} 
& \multicolumn{4}{c}{ No. $(\%)$ of Participants } \\
\cline { 2 - 5 } Health Care Professional & Phase $\mathbf{2}(\boldsymbol{n}=\mathbf{3 5})$ & Phase $\mathbf{3}(\boldsymbol{n}=\mathbf{3 0})$ \\
\hline Nurse, management & 3 & $(9)$ & 3 & $(10)$ \\
Nurse, clinical & 8 & $(23)$ & 8 & $(27)$ \\
Pharmacist, management & 4 & $(11)$ & 6 & $(20)$ \\
Pharmacist, clinical & 11 & $(31)$ & 6 & $(20)$ \\
Pharmacy technician & 2 & $(6)$ & 2 & $(7)$ \\
Physician & 2 & $(6)$ & 2 & $(7)$ \\
Other & 5 & $(14)$ & 3 & $(10)$ \\
\hline
\end{tabular}


This single copy is for your personal, non-commercial use only.

For permission to reprint multiple copies or to order presentation-ready copies for distribution, contact CJHP at cjhpedit@cshp.ca

Table 3. Health Care Professionals' Agreement on the 20 Issues Retained from Phase 2 of the Delphi Process

\begin{tabular}{|c|c|}
\hline Professions with $\geq 80 \%$ Agreement* & $\begin{array}{c}\text { Issues with "Agree" or "Strongly Agree" Rating from } \geq 80 \% \\
\text { of Participants in a Professiont }\end{array}$ \\
\hline $\begin{array}{l}\text { professions (nurses, pharmacists, } \\
\text { physicians) }\end{array}$ & $\begin{array}{l}\text { - Drug that can be administered by only one route } \\
\text { - Drug that requires airway management before administration } \\
\text { - Medication that can be given only via a central line } \\
\text { - Neuromuscular blocking agent } \\
\text { - Antineoplastic agent } \\
\text { - Anesthetic agent } \\
\text { - Cytotoxic medication }\end{array}$ \\
\hline $\begin{array}{l}2 \text { professions } \\
\text { Nursing and pharmacy }\end{array}$ & $\begin{array}{l}\text { - Drug that must always be diluted before administration } \\
\text { - Medication with a significant risk of harm when administered improperly } \\
\text { - Medication to be given by intrathecal route } \\
\text { - Parenteral medication that requires in-line filter for administration } \\
\text { - Medication with extravasation risk, highly irritating IV antibiotic, vesicant } \\
\text { - Concentrated electrolyte formulation }\end{array}$ \\
\hline Nursing and physicians & ( \\
\hline Pharmacy and physicians & None \\
\hline $\begin{array}{l}1 \text { profession } \\
\text { Nursing }\end{array}$ & $\begin{array}{l}\text { - Drug names that look alike and sound alike (LASA) } \\
\text { - Medication that requires specific administration timing, such as drugs } \\
\text { that must be given very slowly and those that require specific time limits } \\
\text { because of risks if given too rapidly } \\
\text { - Medication that has a minuscule volume dose or a high incidence of } \\
\text { calculation/dosage errors }\end{array}$ \\
\hline Pharmacy & $\begin{array}{l}\text { - Multi-part drug (e.g., vaccine and diluent) } \\
\text { - Medication that should not be crushed or split } \\
\text { - Medication that must be shaken before administration } \\
\text { (mostly for oral formulations) } \\
\text { - Medication that requires special handling }\end{array}$ \\
\hline Physicians and others & None \\
\hline
\end{tabular}

Table 4. Top 10 Most Essential Issues Retained after Phase 3 of the Delphi Process

Issue Retained Mean Essentialness Score (0-100)

Drug that requires airway management 90

before administration

Cytotoxic medication* 80

$\begin{array}{ll}\text { Medication with a significant risk of harm when } & 80 \\ \text { administered improperly } & 80\end{array}$

Neuromuscular blocking agent $\quad 79$

Concentrated electrolyte formulation $\quad 79$

$\begin{array}{ll}\text { Antineoplastic agent* } & 77\end{array}$

Medication that can be given only via a central line $\quad 77$

Drug that must always be diluted before administration $\quad 74$

Medication that has a minuscule volume dose or a high 74

incidence of calculation/dosage errors

Drug names that look alike and sound alike 71

*Issue was eliminated from further consideration because of the presence of pre-existing and well-accepted pictograms.

\section{Phase 4: Semiotic Analysis and Pictogram Development}

Semiotic analysis for the 10 retained issues revealed several themes, which were used to create the pictograms (Table 5). Issues for which semiotic analysis revealed pre-existing and well-established pictograms were excluded from pictogram development; this was the situation for "cytotoxic medication" and "antineoplastic agent". When semiotic analysis revealed multiple concepts encompassed within a single issue, the issue was split into its core concepts, and the semiotic analysis was repeated for each of the subordinate issues. This was the situation for "medication that has a minuscule volume dose or a high incidence of calculation/dosage errors", which was split into the following 2 issues: "medication that has a minuscule volume dose" and "medication that has a high incidence of calculation/ 
Table 5 (part 1 of 2). Results of Phase 4 of the Delphi Process

This tables shows preliminary pictograms with their preference rates (as number and percent of participants), in descending order of preference, ${ }^{*}$ along with the graphic elements extracted from semiotic analysis that were present in more than $50 \%$ of analyzed images from either Google or Yahoo search engines

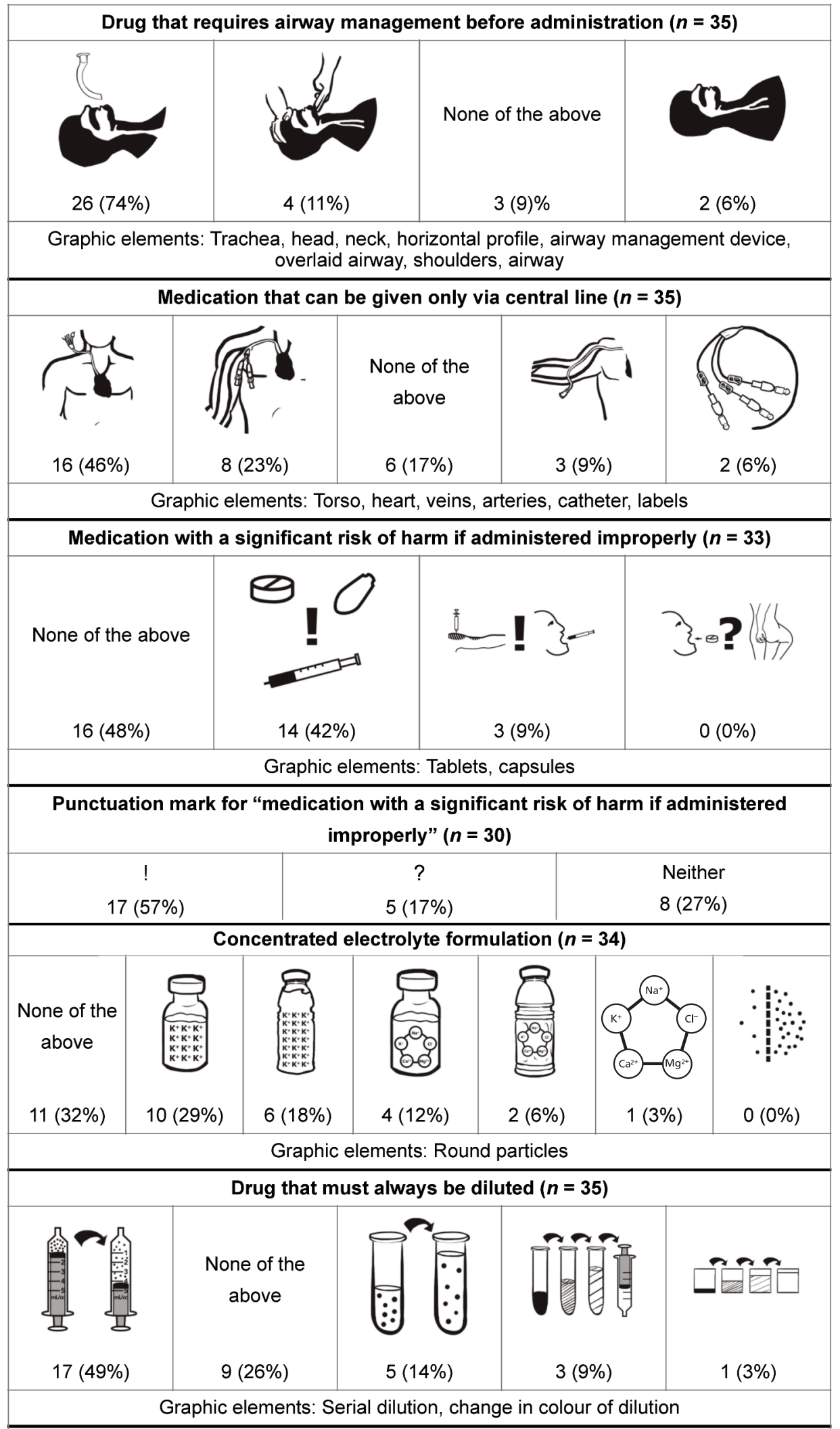




\section{Table 5 (part 2 of 2). Results of Phase 4 of the Delphi Process}

This table shows preliminary pictograms with their preference rates (as number and percent of participants), in descending order of preference, ${ }^{*}$ along with the graphic elements extracted from semiotic analysis that were present in more than $50 \%$ of analyzed images from either Google or Yahoo search engines

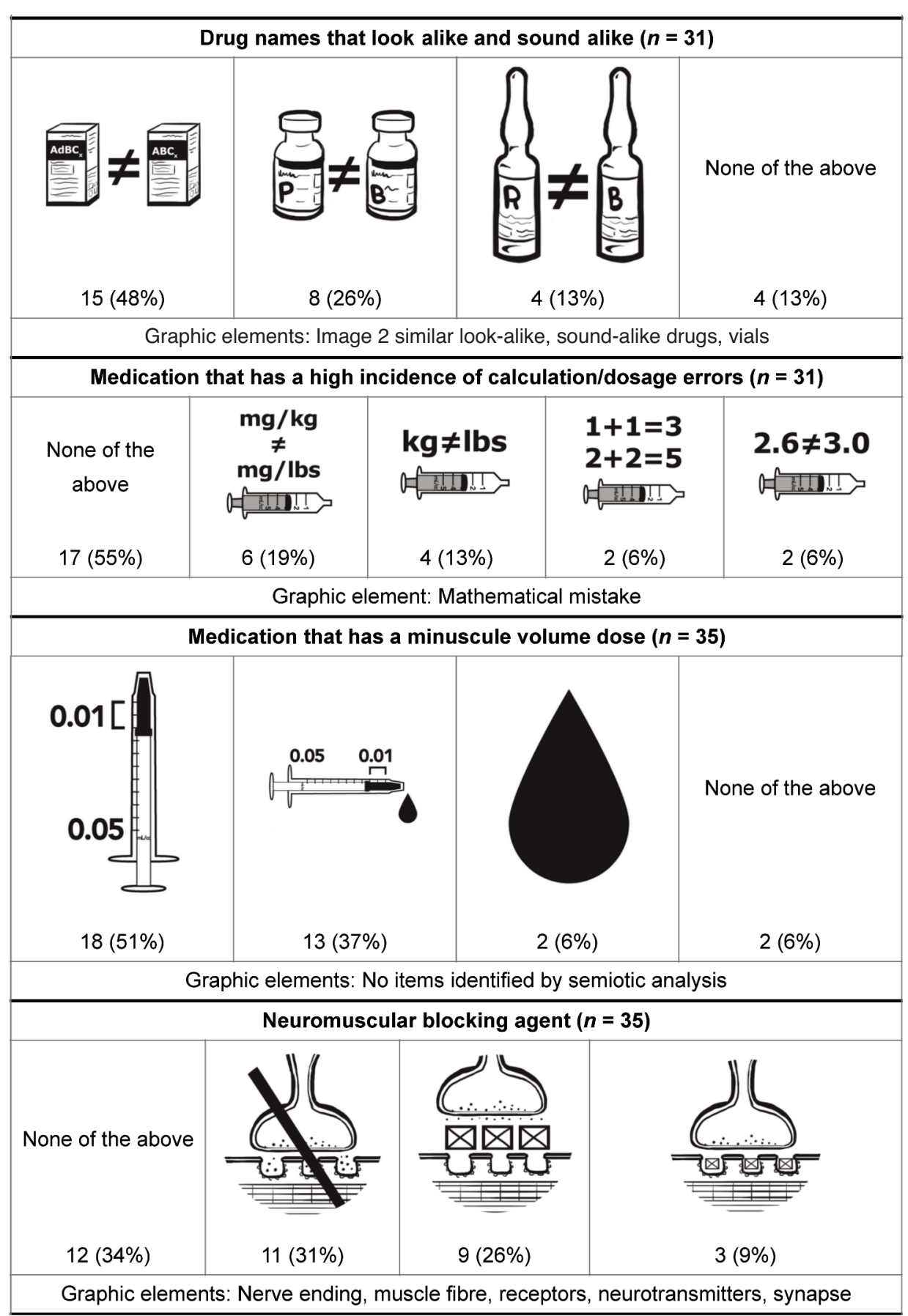

*The $n$ value for each issue or high-alert drug class indicates the number of participants who ranked the pictograms for that issue. 
dosage errors". This was also the situation for "medication with a significant risk of harm when administered improperly", for which a new issue was added to identify the best punctuation mark for representing "risk of harm". For 5 of the 9 sets of pictograms proposed, participants selected a preferred pictogram. For the remaining 4 sets of pictograms proposed, "None of the above" was the most common selection.

\section{DISCUSSION}

As determined in previous studies, the use of pictograms has the potential to increase comprehension of medication instructions. ${ }^{9}$ From a health care professional's perspective, better comprehension may decrease errors during medication management, thereby improving medication safety. As recommended by Montagne, ${ }^{9}$ the first step is to develop appropriate pictograms and validate them to ensure comprehension and to maximize their effect.

Of the top 10 medication safety issues and high-alert drug classes established through this study, both "cytotoxic medication" and "antineoplastic agent" were removed from the list, because of the presence of pre-existing and well-accepted pictograms. Only 2 high-alert drug classes, "neuromuscular blocking agent" and "concentrated electrolyte formulation", were identified among the 8 remaining issues that would benefit from safety pictograms. The resulting emphasis on medication safety issues may be due to perceived greater pertinence of these issues, relative to high-alert drug classes, for the implementation of safety pictograms by pharmacists, nurses, and physicians.

The agreement rate for issues needing safety pictograms varied greatly across the health care professions. Of the issues selected during phase 2 , physicians agreed to many fewer issues requiring pictograms $(7 / 20)$ than pharmacists $(17 / 20)$ and nurses $(16 / 20)$. This difference may be attributable to relative exposure to medication management errors, with both pharmacists and nurses spending more time managing medications than physicians. It is also possible that time spent managing medications is indicative of the perceived risk of medication errors, which could explain the similarity in the number of issues agreed upon by nurses and pharmacists. Nurses and pharmacists maintain separate practices, and each profession is therefore exposed to different factors contributing to medication errors; this difference in exposure could explain the differences in issues upon which each profession agreed. All of the issues identified by physicians as possibly benefiting from safety pictograms were also identified by nurses and pharmacists. With lesser exposure to medication errors, physicians identified the "core" medication safety issues that are most evident; this may explain why all issues with a high level of agreement among physicians also had a high level of agreement among pharmacists and among nurses.

Of the 10 medication safety issues and high-alert drug classes initially identified, 8 were retained for semiotic analysis and pictogram development, one of which was subdivided into 2 issues ("medication that has a minuscule volume dose" and "medication that has a high incidence of calculation/dosage errors"); in addition, 1 new issue was created to assess the best punctuation to be used to represent "risk of harm". Hence, a total of 10 medication safety issues were retained for consideration (9 involving pictogram development and 1 involving selection of punctuation), 6 of which were initially suggested by ISMP Canada. This finding shows a high congruence between the issues and high-alert drug classes suggested by the targeted health care professionals and those identified by ISMP Canada, perhaps because the ISMP Canada suggestions were based on incident reports from health care professionals. Of the 4 non-ISMP Canada medication safety issues retained, all were similar to issues suggested by ISMP Canada, providing either a more specific or broader cautionary message. For example, the issue "medication that can be given only via a central line" is a more specific version of the ISMP Canada issue "medication that can be administered by only one route". Conversely, "medication with a high incidence of calculation/dosage errors" is a broader medication safety issue, encompassing the issue of "multi-part drugs" suggested by ISMP Canada. "Cytotoxic drug" is an issue similar to the high-alert drug class "antineoplastic agent" suggested by ISMP Canada. "Medication with a significant risk of harm when administered improperly" is a very broad issue encompassing many ISMP Canada suggestions and high-alert drug classes. The congruence among issues selected by participants and suggestions from ISMP Canada, as well as the congruence within a varied pool of health care professionals, confirms the consensus that this Delphi process sought to ratify and the practical relevance of the selected issues.

Although this study sought to determine the situations that would benefit from implementation of safety pictograms, it is possible that the issues retained after phase 3 do not specifically meet this goal. Participants may have responded by selecting issues that they thought would be better represented by pictograms, rather than selecting issues that were most in need of safety pictograms.

Semiotic analysis of the 10 issues retained after phase 3 revealed pre-existing pictograms for both "cytotoxic agent" and "antineoplastic agent". For this reason, these 2 issues were excluded from pictogram development. The issue "medication that has a minuscule volume dose or a high incidence of calculation/ dosage errors" was divided into 2 distinct issues for pictogram development, as it was thought that the issue encompassed 2 separate ideas that would be difficult and confusing to combine graphically. Finally, a semiotic analysis of different punctuation marks was performed to better identify the best choice to represent a "risk of harm".

It seems that medication safety issues with more graphic elements identified by semiotic analysis were preferred by health care professionals. For example, $74 \%$ of participants selected 
the same pictogram for "medication that requires airway management before administration", for which 8 graphic elements were identified; in contrast, $55 \%$ of participants selected "none of the above for "Medication with a high incidence of calculation/dosage errors", for which only 1 graphic element was identified. However, even though 5 graphic elements were identified for "neuromuscular blocking agent", a majority of participants (34\%) selected "none of the above". This result may reflect the fact that the proposed pictograms for this issue depicted a microscopic concept that few people have ever seen. Furthermore, although semiotic analysis of "medication with a minuscule volume dose" revealed no graphic elements, a majority of participants $(51 \%)$ selected the same pictogram. This result may reflect the simplicity of the image, as well as the lack of potentially confusing elements. For issues thought to have more abstract and less tangible meanings, fewer graphic elements were extracted from the semiotic analysis. These abstract issues were not selected as preferred pictograms. Therefore, abstract concepts seem to yield pictograms that are poorly accepted, possibly because of their lack of tangibility.

Several limitations of this study must be considered. First, respondents to the ISMP Canada newsletter were self-identified experts, as opposed to being independently identified, which allowed for much variation in medication management expertise. However, given that all participants were from a pharmacy, nursing, or physician background, it was anticipated that the targeted participants would have general proficiency in the realm of medication management. Furthermore, although the panel of experts spanned many disciplines, it drew only from a Canadian pool and may thereby have reflected only medication safety issues specific to Canada. The study was also subject to a high attrition rate among the participating medication management experts, which can be attributed to refinement of the pool of self-identified experts. Participants who responded to an earlier phase of the study but did not respond to a later phase may have dropped out because of a perceived lack of expertise in the field or a perceived lack of relevance of the study; in this way, the expert pool was partially refined to both concerned and expert health care professionals. The decreasing attrition rate from phase 1 to phase 4 is indicative of this refinement of the panel of experts; in this manner, consensus was achieved by consistent rather than sporadic participation, as is typical of the Delphi method. ${ }^{13}$

\section{CONCLUSION}

This study aimed to determine the situations in which safety pictograms are needed. Seven medication safety issues and 3 high-alert drug classes were identified by a panel of medication safety experts as potentially benefiting from the development and use of safety pictograms. Following semiotic analysis, a total of 9 items proceeded to pictogram development, and for 5 of these items, participants selected a preferred pictogram. Future studies will aim to validate the preferred pictograms and modify those with no preferred selection until a set of universally validated pictograms for medication administration safety are developed.

\section{References}

1. Krähenbühl-Melcher A, Schlienger R, Lampert M, Haschke M, Drewe J, Krähenbühl S. Drug-related problems in hospitals: a review of the recent literature. Drug Saf. 2007;30(5):379-407.

2. Dean B, Schachter M, Vincent C, Barber N. Prescribing errors in hospital inpatients: their incidence and clinical significance. Qual Saf Health Care. 2002;11(4):340-4.

3. Ghaleb MA, Barber N, Franklin BD, Wong ICK. The incidence and nature of prescribing and medication administration errors in paediatric inpatients. Arch Dis Child. 2010;95(2):113-8.

4. Schachter M. The epidemiology of medication errors: How many, how serious? Br J Clin Pharmacol. 2009;67(6):621-3.

5. Ehrmann O. Les erreurs médicamenteuse en pédiatrie hospitalière [dissertation]. Lyon (France): Université de Lyon; 2012.

6. de Vries EN, Ramrattan MA, Smorenburg SM, Gouma DJ, Boermeester MA. The incidence and nature of in-hospital adverse events: a systematic review. Qual Saf Health Care. 2008;17(3):216-23.

7. United Nations Committee of Experts on the Transport of Dangerous Goods (UNCETDG). Globally harmonized system of classification and labelling of chemicals (GHS): classification criteria for chemicals presenting physical hazards. Working document ST/SG/AC.10/30/Rev.6. United Nations; 2015 [cited 2016 Jul 6]. Available from: www.unece.org/index.php?id=40514

8. WHMIS pictograms 2015. Canadian Centre for Occupational Health and Safety; 2015 [cited 2015 Jul 6]. Available from https://www.ccohs.ca/ products/posters/pdfs/WHMIS_2015.pdf

9. Montagne M. Pharmaceutical pictograms: a model for development and testing for comprehension and utility. Res Social Adm Pharm. 2013;9(5): 609-20.

10. Definitions of terms. Toronto (ON): Institute for Safe Medication Practices Canada; 2014 [cited 2016-07-06]. Available from: https://www.ismpcanada.org/definitions.htm

11. Harris PA, Taylor R, Thielke R, Payne J, Gonzalez N, Conde JG. Research electronic data capture (REDCap) - a metadata-driven methodology and workflow process for providing translational research informatics support. J Biomed Inform. 2009;42(2):377-81.

12. Korenevsky A, Vaillancourt R, Pouliot A, Revol M, Steed E, Besançon L, et al. How many words does a picture really tell? Cross-sectional descriptive study of pictogram evaluation by youth. Can J Hosp Pharm. 2013;66(4):219-26.

13. Hsu CC, Sandford BA. The Delphi technique: making sense of consensus. Pract Assess Res Eval. 2007;12(10):1-8.

Régis Vaillancourt, PharmD, is with the Children's Hospital of Eastern Ontario, Ottawa, Ontario.

Annie Pouliot, PhD, is with the Children's Hospital of Eastern Ontario, Ottawa, Ontario.

Kim Streitenberger, RN, is with the Institute for Safe Medication Practices Canada (ISMP Canada), Toronto, Ontario.

Sylvia Hyland, BScPhm, MHSc, is with the Institute for Safe Medication Practices Canada (ISMP Canada), Toronto, Ontario.

Pierre Thabet, BSc, is with the Children's Hospital of Eastern Ontario, Ottawa, Ontario.

\section{Competing interests: None declared.}

\section{Address correspondence to:}

Dr Régis Vaillancourt

Children's Hospital of Eastern Ontario

401 Smyth Road

Ottawa ON K1H 8L1

e-mail: rvaillancourt@cheo.on.ca

Funding: This study was financially supported by a research grant from the Medbuy Research, Education and Development Fund, which helped to pay for a research assistant. The funder also supplied a list of its member hospitals for initial distribution of the invitation to participate, but had no role in the design of the study, the collection or analysis of data, the preparation of the manuscript, or the decision to publish. 